Article

\title{
The Influence of Negative Workplace Gossip on Knowledge Sharing: Insight from the Cognitive Dissonance Perspective
}

\author{
Xiaolei Zou, Xiaoxi Chen * ${ }^{\mathbb{D}}$, Fengling Chen, Chuxin Luo and Hongyan Liu * \\ School of Management, Jinan University, Guangzhou 510632, China; zouxiaol@stu2019.jnu.edu.cn (X.Z.); \\ fanychen@stu2017.jnu.edu.cn (F.C.); luochuxin@dingtalk.com (C.L.) \\ * Correspondence: txiaoxi@jnu.edu.cn (X.C.); hongyanliu@jnu.edu.cn (H.L.)
}

Received: 4 March 2020; Accepted: 15 April 2020; Published: 17 April 2020

check for updates

\begin{abstract}
Increasing attention is drawn to the effect of workplace gossip on the organization. Negative workplace gossip is a negative evaluation of others behind their back in the workplace. Based on the cognitive dissonance theory, the study explored the relationship between negative workplace gossip and knowledge sharing, through the mediation of organizational trust and the moderation of self-efficacy. The regression results of a two-stage questionnaire survey on 173 Chinese employees suggested that negative workplace gossip negatively influenced employees' knowledge sharing through organizational trust. Additionally, findings also showed that self-efficacy moderated the mediation of organizational trust in the relationship between negative workplace gossip and knowledge sharing. This research provided a new theoretical perspective on the impact of workplace gossip, which has management implications for informal communication and team-building.
\end{abstract}

Keywords: workplace gossip; knowledge sharing; organizational trust; self-efficacy

\section{Introduction}

Workplace gossip is defined as informal conversation or evaluation (i.e., positive or negative) about a member beyond the person's hearing [1], typically involving unproven details. Just as a famous proverb says, 'Good news never goes beyond the gate, while bad news spreads far and wide', gossip spreads rapidly and influences broadly. As a channel of informal communication, workplace gossip is a common phenomenon in the organization. According to an investigation, $66 \%$ of social topics in employee conversations are about others, and $14 \%$ of workplace coffee-break chat is about gossip [2]. That makes workplace gossip an unavoidable management problem. Prior organizational behavioral literature indicates that workplace gossip is a deviant behavior involving dull and malicious talks [3-5] and is associated with less proactive behaviors, creativity [6,7], and higher turnover of the gossip target [8]. Recently, some studies show that workplace gossip also has positive consequences, including the improvement in performance, less free-riding behaviors, high willingness to obey organizational order, more contributions to make group decisions [9-12]. The competing results above suggest that it is necessary to further examine the influence of workplace gossip.

However, academic research devotes little attention to what gossipers perceive and experience when they share this non-official information and personal judgments in the organization $[13,14]$. Gossip is viewed as a mean of informal knowledge sharing, and this valuable personal knowledge is taken as personal property in workplace competition [15]. Like human capital, knowledge sharing encourages employees' sustainable performance or dynamic capabilities to work sustainably, thus further accelerating organizational sustainability [16-18]. Unlike gossip, knowledge sharing is a self-defense mechanism, which is conditioned by many internal and external factors (i.e., social 
relationships, organization power, trust) $[19,20]$. The employees would not always share knowledge with others actively in direct communication to maintain their psychological safety or personal competitiveness [21]. Hence, the social dilemma of knowledge sharing emerges when employees face a choice between sharing knowledge for the organization benefit and hiding personal resources for their own advantages. This raises the following question: is gossip the barrier to or the enabler of formal sharing knowledge? Such research is of importance because gossip is a typical informal communication that exerts a widespread effect on employee's work life, and knowledge sharing plays a central role in sustainable development. Therefore, we aimed for a more specific understanding of workplace gossip's effect on gossipers' behaviors, such as knowledge sharing.

To address this question, we proposed a new conceptual framework that considered how gossipers would alter knowledge sharing behavior through their belief change (organizational trust) based on the cognitive dissonance theory. Organizational trust refers to trust relations with co-workers, supervisors, and organization [22]. According to cognitive dissonance theory [23], the dissonance is aroused when people find that their behaviors may be inconsistent with their cognition (i.e., keeping the psychological contract with the organization, positive self-consistency [24,25]). Workplace gossip is usually regarded as deviant behavior and is generally frowned upon by social norms [1,26]. With the behavior conflicting with social cognition, gossipers might feel the pressure. In order to reduce dissonance, they would like to adjust their cognition and make it reasonable to attribute their gossip behaviors to external factors, such as supervisors' unethical behaviors, egoistic organizational values, leading to less trust in the organization [27]. Moreover, the lack of trust rooted in a personal relationship hinders the intent of knowledge sharing [28]. This study also considered self-efficacy, a self-related factor, into the relationship between workplace gossip and knowledge sharing. Self-efficacy is people's belief or evaluations about their abilities to produce designated levels of performance [29]. Specifically, there have been published studies on the association between perceived self-efficacy and cooperative behavior in an organization (e.g., [30-32]).

In sum, this study provided contributions to the existing literature in several aspects. First, based on the cognitive dissonance theory, it empirically and theoretically introduced a new framework that linked workplace gossip with knowledge sharing, filling the gap between the informal workplace gossip and formal knowledge sharing. In addition, this study extended empirical evidence on the impact of informal communication within the organization. As mentioned before, workplace gossip is acknowledged as an informal way of obtaining information (e.g., knowledge sharing), both of them relying on the social relationship. So, it helps understand the mechanism of the harmful consequences of informal communication. Third, we enriched the literature on how gossipers feel about themselves after gossiping, a new perspective that few studies have explored [13]. Existing research mainly places emphasis on the influence of gossip on the perceptions and behaviors of gossip target or the antecedents of negative gossip. Fourth, based on the cognitive dissonance theory, we explored the internal process of knowledge sharing on the individual level by including workplace gossip and also broadened the antecedents of knowledge sharing. Most of the knowledge sharing studies pay attention to how to gain and share knowledge on the organizational and strategic level [33], so we echoed the call of Foss et al. [34] for more research on how and why personal knowledge sharing happen from the perspective of individual cognition.

\section{Theoretical Background and Hypothesis}

\subsection{Workplace Gossip}

Workplace gossip is an evaluative talk about a non-present third member when a member communicates with another member in the organization [1]. Differentiated from other informal communication, workplace gossip serves as the exchange of information, rather than entertainment, purposelessness, non-evaluative talk, such as news about a star [35]. Work-related gossip focuses on the target's work (i.e., performance, interpersonal relationship with other members, attitude towards 
management problem), treated as a source of more professional, reliable messages compared with non-work-related gossip [36].

In terms of nature or the valence, workplace gossip is categorized into negative gossip and positive gossip $[1,4,13]$. Negative workplace gossip is a negative evaluation of a member behind his or her back, such as a complaint about excessive sick-days of the member, while positive workplace gossip relates to the positive evaluation of others, such as appreciation of a colleague's promotion $[1,13]$. In this study, we were interested in negative workplace gossip because negative gossip appears to have a wider effect on people's behavior than the positive one [37]. According to the job positions of the gossip target, such as supervisors and peers, Brady validated that a gossiper would like to gossip about a supervisor and a co-worker for different motivations [1]. For example, managers are more prone to become the negative gossip target due to bias or inadequacy of information about high-status top management [38]. Ellwardt et al. confirmed that employees shared their negative gossip about distrusted managers [39]. So, we measured negative gossip information about both co-workers and supervisors in this study.

\subsection{Knowledge Sharing}

Knowledge sharing refers to the willingness of an organization member to share the knowledge they have owned [40-42]. Usually, knowledge is divided into explicit knowledge (i.e., document, report, fact) and tacit knowledge (i.e. belief, mindset, know-how). Specifically, tacit knowledge can be typically learned only through experience and is usually hard to codify because it is highly personal, subjective, and typical job- or situation-specific [43,44]. However, tacit knowledge holders do not realize that they possess it [45]. Many scholars place the increasing importance of knowledge sharing because not only does it provide the organization with a competitive human capital resource that is rare and inimitable [46] but also cultivates a continuous learning culture [47]. So, the organization can reach sustainable success through knowledge sharing [48,49].

Some studies define gossip as a special form of knowledge for the reason that people sometimes think gossip contains some crucial, inaccessible information, but acts as a "poor method of increasing one's knowledge" [50]. Especially, Bertolotti and Maganai created a concept-gossip-based knowledge- to explore the role of gossip in group knowledge by an epistemological analysis [51]. Unlike gossip, knowledge is viewed as a resource of improving performance, promoting status, but loses its value once shared with others, inducing the social dilemma. However, in this study, we considered knowledge as acquired personal work experience, job-related skills, unique ideas, or non-standard know-how in the formal workplaces, but workplace gossip is a negative work-related evaluation of the absent organizational member, which occurs in workplaces.

\subsection{Cognitive Dissonance Theory}

Cognitive dissonance theory (CDT) presents the origin of dissonance and coping strategy to reduce dissonance. Dissonance is a feeling of tension or discomfort that originates from the discrepancy between two incompatible cognitions and motivates people to alter their attitude or behaviors [23,52]. On the contrary, consonance originates when one cognition reaffirms another one. Festinger described cognition as a broad mental process, such as attitude, perception of one's behavior, and belief [23]. Typically, there are four steps of dissonance arousing and reduction: cognitive discrepancy, dissonance, motivation, and dissonance reduction [53]. Dissonance would appear in various situations. For example, smokers who believe smoking undermines their health continue to smoke and feel dissonance, which is inconsistent with their belief. In management research, CDT is used to explain the mechanism of decision-making, counter-attitudinal behaviors, the conflict between employee and organizational value, and so on [54-56].

In order to reduce this psychological discomfort, people are motivated to seek coping strategies to reach consistency between behavior and cognition. In general, the process of dissonance reduction relies on which one, cognition or behavior, is easier to change. There are several usual types of solutions: 
(1) change attitude towards the behavior; (2) adjust behavior in accordance with the attitude; (3) justify the behavior [53].

\subsection{Negative Workplace Gossip and Organizational Trust}

From the cognitive dissonance theory, people are inclined to keep consistency (consonance) between behavior and cognition [23,52]. In enterprises, there are some regulations and rules that forbid spreading negative gossip. For example, one of Alibaba Company's six new enterprise values is 'Trust makes everything simple', which functions as a psychological contract between employees and the organization. When a gossiper tells others some negative gossip about a non-present member, the gossiper has potentially violated the organization's value and will face a dissonance between cognition (I 'm a good employee) and behavior (I made deviant behavior). To reduce this discomfort, gossipers might adopt three rationalization strategies. The first solution is that they may adjust their gossip behavior to fit the organization, but it is a pity that they have engaged in gossiping, which could not change. The second coping strategy is to change their attitude towards themselves by admitting to being immoral or violators of the organizational norm. However, it is unlikely to occur because people usually prefer a defensive strategy for self-protection and keep a positive self-view [57], especially in East-Asian culture, when confronted with an explanation of their non-normative gossip behavior. Besides, gossipers would produce an anxiety that an unfavorable impression or reputation is left on others, which would decrease the likability and attractiveness of the gossiper $[38,58]$. So, gossipers are more likely to choose the third resolution, changing their perception of the action of gossip. They tend to give a good justification for negative workplace gossip behavior and alter belief into that it is the organization that itself indeed is untrustworthy and fails to satisfy employees. In other words, negative gossip is reasonable [58,59]. Then, gossiper would attribute their non-normative behavior to situational organization factors, such as supervisor ostracism [60], organizational culture problem [61,62], injustice [13,63], team free-riding behavior [12], leading to a decrease in trust. Some studies provide evidence that negative workplace gossip has led to mutual suspicion among employees, even involving a broader scope of this feeling in the organization [64].

According to the above, we proposed that:

H1: Negative workplace gossip decreases the organizational trust of gossipers.

\subsection{Organizational Trust and Knowledge Sharing}

Organizational trust can be sorted into lateral trust among peers and the vertical trust between employees and their supervisors [22,27,65]. Especially, Zhang et al. [61] indicated that the top-down structure of trust, also called the China model, might exert further influence on organizational structure and culture, such as trust. In this study, organizational trust implied a broad scope of trust on the representatives of the organization like managers and coworkers, and not a specific person, meaning a member's belief in the assessment of organization whether it meets moral or contractual promises towards its employees [39].

It is considered to be risky to share knowledge with others for fear of losing their knowledge advantage, but a relationship based on trust helps mitigate this perceived risk [66,67]. Following the cognitive dissonance theory, people are motivated to keep consistency (consonance) and avoid inconsistency (dissonance). Where there is more trust, there will be more sharing, and less trust means less share. To some extent, organizational trust reflects a positive expectation of the member who receives value or positive consequence from the organization [27]. Therefore, people are willing to exchange their knowledge with others in a trustworthy organization, and lack of trust is a barrier to sharing knowledge [68]. Previous literature empirically validates that trust has a positive impact on knowledge sharing (e.g., [31,66,69]). Specifically, Rutten et al. confirmed that implicit knowledge sharing was more affected by trust than explicit knowledge sharing, and low-level trust decreased knowledge sharing between colleagues [28]. 
With a negative attitude towards and a low level of trust in the organization, gossipers try to obtain their consonance and continue to behave in a way, which is consistent with their attitude, such as less favorable behavior for the organization. Aiming to maintain consonance, less knowledge sharing would be showed by gossipers due to less organizational trust caused by negative gossip. Consequently, we posited that:

H2: A lower level of organizational trust leads to a lower level of knowledge sharing of gossipers; organizational trust mediates the relationship between negative workplace gossip and knowledge sharing.

\subsection{Self-efficacy Serviced as A Moderator}

In this study, we selected self-efficacy as the role of individual differences in buffering the cognitive dissonance of gossiping. Bandura conceived self-efficacy as the belief in one's ability to achieve for a given task, and self-efficacy contributes to employees' performance and even the organization's performance [23]. Knowledge self-efficacy refers to the ability to come out of the solutions to problems as well as to make a decision independently. Most studies demonstrate that self-efficacy is a significant predictor of knowledge sharing [32,70,71]. People with high self-efficacy are more likely to express themselves and influence others than low self-efficacy ones [72]. The high self-efficacious individual usually suffers less depression and prefers to seek a comfortable way to work, resulting in less cognitive dissonance [23]. For example, Heuwen et al. found that a high level of self-efficacy could promote service workers' ability to solve their emotional dissonance [73].

Building on the above logic, we expected that self-efficacy plays a moderating role in the positive relationship between organizational trust and knowledge sharing. Gossipers with high self-efficacy are characterized by well coping with dissonance from negative gossip and embracing a stable belief for the organization, such as refutation of belief-inconsistent information [57], which means that they have a lower degree of reduced organizational trust. Thus, high self-efficacious gossipers are confident in influencing others and sharing knowledge regardless of their organizational trust level compared with low self-efficacious gossipers. Conversely, low self-efficacious members with low organizational trust tend to adopt an emotion-focused coping strategy. They are vulnerable to suffer anxiety from the environmental factors or are encouraged to behave what others want them to do, leading to a significant change in knowledge sharing. Accordingly, we hypothesized the followings:

H3a: Self-efficacy moderates the positive relationship between organizational trust and knowledge sharing.

H3b: Self-efficacy moderates the mediation effect of organizational trust, which is stronger when gossiper's self-efficacy is low.

Given the above hypothesis, we develop our conceptual model as below (Figure 1).

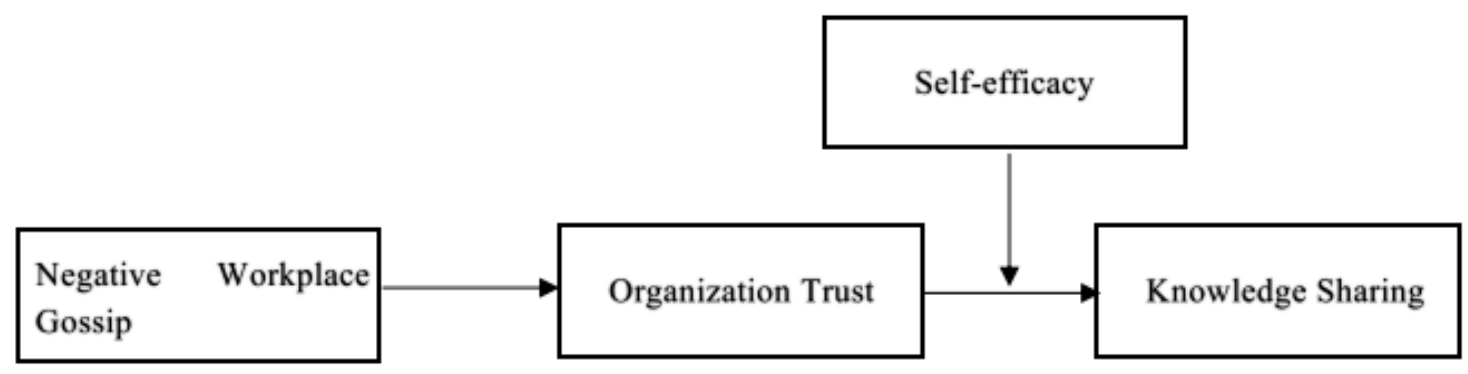

Figure 1. Hypothesized conceptual model. 


\section{Methods}

\subsection{Participants and Procedures}

Participants were full-time employees working in Guangdong province. All participants finished the survey voluntarily. The snowball sampling method was used to enlarge the sample size, through which the electronic survey was sent to their colleagues or supervisors in a week. All participants were invited to read and sign consents of this investigation. We conducted a two-wave survey to reduce common method bias caused by self-report. After a month, participants who finished the first survey were asked to fill the second survey. The last four numbers of their mobile phones were used to match the first and the second survey. In the first survey (T1), participants needed to finish the demographic information and fill workplace gossip items. In the second wave (T2), participants filled scales, including organizational trust scale, self-efficacy scale, and knowledge sharing scale. After completing the surveys, each participant received RMB 5-10 yuan as an incentive.

In the first stage, a total of 1429 questionnaires were collected, and 875 questionnaires were valid (response rate $=61.2 \%$ ). In the second data collection, some samples who completed the first survey did not finish the second survey. Besides, some participants did not offer their accurate phone tail numbers, resulting in code inconsistency. So, we could not match their two-point codes and missed these samples. At last, 173 surveys were valid in a total of 420 questionnaires (response rate $=41.2 \%$ ). We took the final 173 participants who finished scales at both time points as the sample of this study. Based on demographic information detection, more than $50 \%$ of them was the knowledge worker (see Table 1).

Table 1. Demographic information.

\begin{tabular}{cccc}
\hline Demographic & Category & Frequency & Percentage \\
\hline Gender & Male & 67 & $38.73 \%$ \\
& Female & 106 & $61.27 \%$ \\
\hline Age & $>18, \leq 25$ & 59 & $34.10 \%$ \\
& $>25, \leq 30$ & 59 & $34.10 \%$ \\
& $>30, \leq 40$ & 47 & $27.17 \%$ \\
& $>40, \leq 60$ & 8 & $4.62 \%$ \\
\hline Tenure & $\leq 3$ years & 48 & $27.75 \%$ \\
& $3-5$ year & 44 & $25.43 \%$ \\
& $5-10$ year & 48 & $27.75 \%$ \\
& $\geq 10$ year & 33 & $19.08 \%$ \\
\hline Education & High school & 37 & $21.39 \%$ \\
& Junior college & 47 & $27.17 \%$ \\
& Bachelor & 81 & $46.82 \%$ \\
& Master & 8 & $4.62 \%$ \\
\hline Position & Grass-root staff & 30 & $17.34 \%$ \\
& Administrative staff & 19 & $10.98 \%$ \\
& Production workers & 5 & $2.89 \%$ \\
& Technical staff & 59 & $34.10 \%$ \\
& Managers & 31 & $17.92 \%$ \\
& Others & 29 & $16.76 \%$ \\
\hline
\end{tabular}

\subsection{Measures}

The survey was composed of the following instruments.

Workplace gossip. To measure negative workplace gossip, we used the 10-item workplace gossip scale (Chinese version) developed by Brady et al. [1]. The scale includes 5 items about gossiping for supervisors and 5 items for co-workers. For example, "in the past month, how often have you vented to colleagues about something that your supervisor has done?", "how often have you questioned a 
co-worker's ability while talking to another work colleague?". The response was rated on a scale of 1 ("never") to 7 ("more than once a day"). The scale reliability of negative workplace gossip in this study was $\alpha=0.90$.

Knowledge sharing. The knowledge-sharing scale is made up of knowledge sharing behavior and willingness with 9 items. Specifically, knowledge sharing behavior was assessed by the six-item scale from Chennaveneni [74] in 2006. To measure willingness, we adopted a tacit knowledge sharing willingness scale developed by Bock and Kim [31]. The sample item is "I'll tell my colleagues when I learn something new", with a seven-point Likert scale from 1 ("never") to 7 ("more than once a day"). The scale reliability in this study was $\alpha=0.95$.

Organizational trust. To measure organizational trust, we used the Chinese version of the 14-item organizational trust scale developed by Chen [75]. The scale is composed of three main contents, including employees' trust in organization, supervisors, and coworkers. For example, participants were asked, "In my work, I believe the company is capable of providing benefits and looking after employees". Participants responded on a five-point scale from 1 ("totally disagree") to 5 ("totally agree"). The reliability of this scale in this study was $\alpha=0.94$.

Self-efficacy. To assess self-efficacy, we used the Chinese version of the 10-item GSES (general self-efficacy scale) developed by Zhang and Schwarzer [76]. The sample item is "If I do my best, I can always solve the problem" or "I am able to think out different solutions to deal with a difficult problem", with a 4-point Likert scale from 1 ("totally disagree") to 4 ("totally agree"). The scale reliability in this study was $\alpha=0.91$.

Control variables. Previous studies have found that demographic variables, such as position, education, and tenure, have a significant effect on knowledge sharing behavior [77], so we controlled these demographic variables. At the same time, we also controlled the two demographic variables: age and gender.

\section{Results}

Data collected in this study were analyzed as described in the following steps. The first step was to calculate the descriptive statistics and correlations between relevant variables. In the second step, we examined the common method variance and multicollinearity problems and then used confirmatory factor analysis (CFA) to test the construct validity (Appendix A Table A1). Finally, a regression model and a bootstrapping procedure were applied to inspect our hypotheses.

The descriptive statistics of the sample and correlations of variables can be seen in Table 2. The internal consistency of all scales in the present study was acceptable (see diagonal). All the demographic variables, such as age and gender, were taken as control variables in all analyses. Table 2 shows that a negative workplace gossip (NWG) had a significantly negative relation with knowledge sharing (KS) $(r=-0.18, p<0.05)$ and organizational trust (OT) $(r=-0.20, p<0.01)$. Organizational trust was significantly positively related to knowledge sharing $(r=0.69, p<0.01)$. The correlation results provided preliminary support for Hypotheses 1 and 2.

To assess the common method bias, Harman's single factor test of major variables was calculated. The results of Harman's single factor test found that every factor's eigenvalue was greater than 1, and the largest factor only explained $31.15 \%(<40 \%)$ of the result, suggesting that this study did not load into one major factor, and a common method variance could not be an influential problem.

We examined the construct validity through CFA by Mplus.7. The model fit indices are Chi-square statistic $\left(\chi^{2}\right)$, degree of freedom (df), the root mean square error of approximation (RMSEA), the standardized root mean square residual (SRMR), the comparative fit index (CFI), and the Tucker-Lewis index (TLI). Results indicated that the hypothesized model (4-factor model) made the best goodness of fit $\left(\chi^{2} / \mathrm{df}=5.716, \mathrm{CFI}=0.895, \mathrm{TLI}=0.888, \mathrm{RMSEA}=0.055, \mathrm{SRMR}=0.066\right)$, which was better than any other models (see Table 3 ). 
Table 2. Descriptive statistics and correlations matrix $(\mathrm{N}=173)$.

\begin{tabular}{|c|c|c|c|c|c|c|c|c|c|}
\hline Variables & 1 & 2 & 3 & 4 & 5 & 6 & 7 & 8 & 9 \\
\hline 1. Gender & - & & & & & & & & \\
\hline 2. Age & 0.02 & - & & & & & & & \\
\hline 3. Tenure & 0.04 & $0.80^{* *}$ & - & & & & & & \\
\hline 4. Education & -0.02 & $0.16^{*}$ & 0.13 & - & & & & & \\
\hline 5. Position & -0.03 & -0.12 & -0.10 & $-0.22 * *$ & - & & & & \\
\hline 6. $\mathrm{NWG}^{1}$ & $0.15^{*}$ & -0.04 & -0.03 & $0.24 * *$ & -0.03 & $(0.90)$ & & & \\
\hline 7. Organizational trust & -0.04 & -0.02 & -0.03 & 0.08 & -0.11 & $-0.20^{* *}$ & $(0.94)$ & & \\
\hline 8. Self-efficacy & -0.04 & $0.17^{*}$ & $0.19 *$ & 0.13 & -0.06 & -0.10 & $0.65^{* *}$ & $(0.91)$ & \\
\hline 9. Knowledge sharing & -0.02 & 0.01 & 0.04 & 0.11 & -0.15 & $-0.18 *$ & $0.69 * *$ & $0.64^{* *}$ & $(0.95)$ \\
\hline Mean & 0.61 & 3.02 & 2.38 & 2.35 & 3.41 & 1.99 & 3.59 & 2.73 & 5.15 \\
\hline SD (Standard deviation) & 0.49 & 0.89 & 1.09 & 0.87 & 1.71 & 0.89 & 0.63 & 0.47 & 1.12 \\
\hline
\end{tabular}

Table 3. Results of alternative models.

\begin{tabular}{cccccccc}
\hline Models & $\chi^{2}$ & df & CFI & TLI & RMSEA & SRMR & $\begin{array}{c}\text { Alternative } \\
\text { Models }\end{array}$ \\
\hline $\begin{array}{c}4 \text {-factor } \\
\text { model }\end{array}$ & 5161.768 & 903 & 0.895 & 0.888 & 0.055 & 0.066 & $\begin{array}{c}\text { NWG, OT, SE, } \\
\text { KS }\end{array}$ \\
\hline $\begin{array}{c}\text { 3-factor } \\
\text { model }\end{array}$ & 5161.768 & 903 & 0.887 & 0.879 & 0.057 & 0.067 & $\begin{array}{c}\text { NWG, OT, SE } \\
+ \text { KS }\end{array}$ \\
\hline $\begin{array}{c}\text { 2-factor } \\
\text { model }\end{array}$ & 12968.832 & 1081 & 0.066 & 0.058 & 0.245 & 0.376 & $\begin{array}{c}\text { NWG + KS, } \\
\text { OT + SE }\end{array}$ \\
\hline $\begin{array}{c}\text { 1-factor } \\
\text { model }\end{array}$ & 12968.832 & 1081 & 0.052 & 0.046 & 0.246 & 0.377 & $\begin{array}{c}\text { NWG + OT + } \\
\text { KS + SE }\end{array}$ \\
\hline
\end{tabular}

Notes: NWG = Negative workplace gossip, OT = Organizational trust, KS = Knowledge sharing, SE = Self-efficacy, $\chi^{2}$ : Chi-square statistic, df: degree of freedom, CFI: comparative fit index, TLI: Tucker-Lewis index, RMSEA: root error of approximation, SRMR: the standardized root mean square residual.

Using hierarchical regression analysis, we examined whether negative workplace gossip led to less organizational trust. From the results of regression analysis in Table 4, we found that there was a significant negative effect between negative workplace gossip and organizational trust $(\beta=-0.24$, $p<0.01$ ), which provided further support for H1.

To test $\mathrm{H} 2$ that negative workplace gossip induces a lower level of organizational trust that, in turn, leads to a lower level of longing for knowledge sharing, we followed the steps suggested by Baron and Kenny [78] for mediation effect, which claims: (a) independent variable can predict a significant variation in mediator; (b) mediator predicts a significant variation in the dependent variable; (c) when controlling the mediator, if the relationship between the independent variable and dependent variable is insignificant, there is a strong mediator.

The results (see Table 4 ) displayed that organizational trust was significantly related to knowledge sharing $(\beta=0.44, p<0.01)$, and negative workplace gossip had a significant influence on organizational trust $(\beta=-0.24, p<0.01)$, which was in support of $\mathrm{H} 2$. To further confirm the mediation effect of organizational trust (NWG $\rightarrow \mathrm{OT} \rightarrow \mathrm{KS}$ ), we adapted bootstrapping of 5000 cases' analyses with $95 \%$ bias-corrected confidence interval. If a zero is not included between the upper and lower limit level of the confidence interval, the indirect effect is supported. As Table 5 exhibits, the mediation effect value of organizational trust was -0.222 , and it was significant without a zero in the confidence interval. After analyzing the mediator variable, the values in Table 5 revealed that the direct effect $\left(c^{\prime}\right)$ turned insignificant, which illustrated that the organizational trust fully mediated the relationship between negative workplace gossip and knowledge sharing. This finding confirmed the $\mathrm{H} 2$ of this study. 
Table 4. Results of regression analyses.

\begin{tabular}{|c|c|c|c|c|c|}
\hline \multirow{2}{*}{ Predictors } & \multicolumn{2}{|c|}{ OT (M1-M2) } & \multicolumn{3}{|c|}{ KS (M3-M5) } \\
\hline & M1 & M2 & M3 & M4 & M5 \\
\hline \multicolumn{6}{|l|}{ Control variables } \\
\hline Gender & -0.09 & -0.01 & -0.05 & 0.04 & 0.07 \\
\hline Age & -0.02 & -0.04 & -0.10 & -0.11 & -0.11 \\
\hline Tenure & -0.03 & -0.03 & 0.08 & 0.05 & 0.07 \\
\hline Education & 0.07 & 0.14 & 0.09 & 0.05 & 0.01 \\
\hline Position & -0.06 & -0.06 & -0.08 & -0.04 & -0.03 \\
\hline \multicolumn{6}{|l|}{ Independent variable } \\
\hline Negative WG & & $-0.24^{* *}$ & & -0.07 & -0.09 \\
\hline \multicolumn{6}{|l|}{ Mediator } \\
\hline Organizational trust & & & & $0.44^{* * *}$ & $0.40^{* * *}$ \\
\hline \multicolumn{6}{|l|}{ Moderator } \\
\hline Self-efficacy & & & & $0.34^{* * *}$ & $0.32 * * *$ \\
\hline \multicolumn{6}{|l|}{ Interaction } \\
\hline $\begin{array}{c}\text { Organizational trust } \times \\
\text { Self-efficacy }\end{array}$ & & & & & -0.23 * \\
\hline $\mathrm{F}$ & 0.66 & $2.42 *$ & 1.08 & $25.86^{* * *}$ & $24.47^{* * *}$ \\
\hline$R^{2}$ & 0.02 & 0.08 & 0.03 & 0.56 & 0.58 \\
\hline$\Delta R^{2}$ & 0.02 & $0.06^{* *}$ & 0.03 & $0.47^{* * *}$ & $0.09^{* * *}$ \\
\hline
\end{tabular}

Notes: ${ }^{* * *} p<0.001,{ }^{* *} p<0.01,{ }^{*} p<0.05$. NWG $=$ Negative workplace gossip, OT = Organizational trust, KS = Knowledge sharing. $\mathrm{F}=$ F-statistics, $R^{2}=$ coefficient of determination.

Table 5. The mediation effect of organizational trust.

\begin{tabular}{ccccc}
\hline Path & Estimate & Standard Error & Lower & Upper \\
\hline $\mathrm{NWG} \rightarrow \mathrm{OT} \rightarrow \mathrm{KS}$ & -0.222 & 0.061 & -0.355 & -0.117 \\
$\mathrm{NWG} \rightarrow \mathrm{KS}\left(\mathrm{c}^{\prime}\right)$ & -0.038 & 0.076 & -0.189 & 0.113 \\
\hline
\end{tabular}

Notes: NWG = Negative workplace gossip, OT = Organizational trust, KS = Knowledge sharing.

H3a proposes that self-efficacy moderates the relationship between organizational trust and knowledge sharing. To test the moderation hypotheses, we used the process in SPSS. Before the regression analysis, the predictor and moderator had been mean-centered to reduce multicollinearity. Results in Table 2 (Model 5) showed that the interaction of organizational trust and self-efficacy was significant $(\beta=-0.23, p<0.05)$. To further illustrate the moderation effect of self-efficacy on the positive relationship between organizational trust and knowledge sharing, we visualized the interaction at high (Mean + 1SD) and low (Mean - 1SD) levels of self-efficacy (see Figure 2). In addition, the simple slope analysis suggested that at a low level of self-efficacy, there was a more significant increase in knowledge sharing when organizational trust increased (effect $=0.869,95 \% \mathrm{CI}=[0.735,1.217])$. At high level of self-efficacy, knowledge sharing increased more slowly with the organizational trust (effect $=0.654,95 \% \mathrm{CI}=[0.360,0.948])$. Although the moderation was statistically significant at both high and low levels, an evident group difference existed between low self-efficacy and high self-efficacy (effect $=0.795, p<0.05$ ). Given the above results, we could support H3a that self-efficacy mitigated the positive relationship between organizational trust and knowledge sharing. 


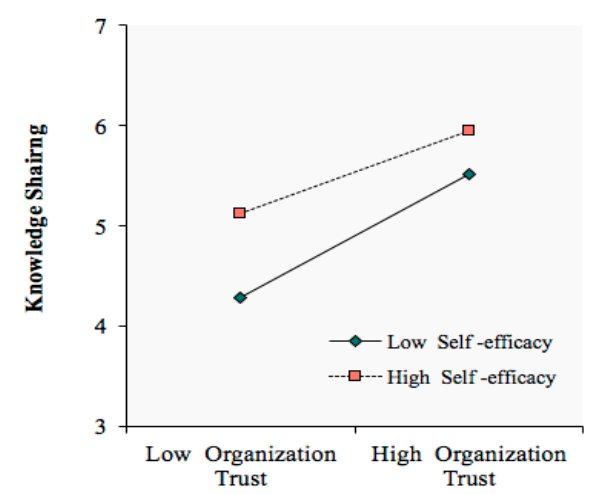

Figure 2. Interactions between self-efficacy and organizational trust in predicting knowledge sharing.

$\mathrm{H} 3 \mathrm{~b}$ indicates that self-efficacy moderates the mediation of organizational trust on the negative relationship between negative workplace gossip and knowledge sharing. Bootstrap analysis of the moderated mediation effect is shown in Table 6. Specifically, the indirect effect of negative workplace gossip on knowledge sharing through the organizational trust was more significant when self-efficacy was low (effect $=-0.078, p<0.05$ ) than when self-efficacy was high (effect $=-0.039, p<0.05$ ). This result lent support to $\mathrm{H} 3 \mathrm{~b}$.

Table 6. The result of moderated mediation.

\begin{tabular}{ccccc}
\hline Moderator & Effect & Standard Error & Lower & Upper \\
\hline Low self-efficacy (-SD) & -0.078 & 0.042 & -0.171 & -0.005 \\
Difference & -0.058 & 0.033 & -0.141 & -0.005 \\
High self-efficacy (+SD) & -0.039 & 0.028 & -0.118 & -0.001 \\
\hline
\end{tabular}

\section{Discussion}

Workplace gossip, as a channel of informal communication in the workplace, might become a potential problem for the sustainability of employee cooperation. As recent papers state, knowledge sharing acts as a key indicator in the social dimension of the sustainable organization, which focuses on employees' well-being and social health $[15,48]$. Therefore, combing with cognitive dissonance theory, we investigated how negative workplace gossip would influence knowledge sharing by exploring the cognition of gossipers, the actors of sharing knowledge. The findings showed that to reduce dissonance caused by non-normative workplace gossip, gossipers would lower their organizational trust and the intent to knowledge sharing. In addition, the high self-efficacious individual had a better coping strategy towards dissonance and confidence about their advantages, which appeared to be less influenced by low organizational trust, and was more willing to share knowledge. Our study extended literature on informal communication and information sharing from a cognitive perspective.

\subsection{Theoretical Implications}

We provided a new theoretical perspective of workplace gossip. Previous research has explored the damaging effects of workplace gossip on employee behavior based on social comparison theory, social learning theory, social exchange theory, evolutionary theory, resource conservation theory, and so on (e.g., $[9,79,80])$. In this study, on the basis of cognitive dissonance theory, we made a contribution to understanding gossipers by exploring their perception and feelings after gossiping. Negative gossip is understood as a violation of organizational norms, so gossipers might be disliked or leave a bad impression on other members [58]. Some gossipers would feel guilty and decrease his or her self-esteem due to harmful consequences they caused [21]. In this study, we focused on explaining the gossiper's attitude towards the organization by introducing organizational trust, which reflects 
employees' positive expectations for organizational competence and fairness. We found that negative workplace gossipers would experience the tension of dissonance after gossip-acting. This dissonance arises from the contradiction between their action (deviant behavior) and their cognition (positive self-evaluation). In order to reduce their dissonance, gossipers would attribute their behaviors to others/environment factors, resulting in the decline of organizational trust. With the aim of being consistent with their lower organizational trust, gossipers will be less available to share knowledge, a behavior for organizational enhancement. In this context, the current study explained how informal communication affected an individual's behaviors and cognition in the workplace and enriched cognitive dissonance theory.

Next, the current study provided insight into knowledge sharing from the individual level. This investigation complemented the cognitive antecedents of knowledge sharing by adding organizational trust. Published research has mostly placed knowledge sharing on the strategic or organizational level and has discussed how shared knowledge contributes to an organization's success, ignoring the individual intent or behavioral factor of knowledge sharing. To explore the individual mechanism of knowledge sharing, we demonstrated that a member's stable perception of the organization, such as their trust and support for the organization, could mirror their attitude towards knowledge sharing. Moreover, although gossipers can convey some information, which could not be obtained from the formal channel, competitive knowledge cannot spread all around as gossip does.

Thirdly, this study demonstrated the moderating effect of self-efficacy, focusing on the boundary effect of individual characteristics on negative workplace gossip and knowledge sharing. Not only did it enrich the integration of self-efficacy and cognition dissonance but also explained the role of individual differences in knowledge sharing. This study empirically concluded that high self-efficacious individuals mastered a better solution to deal with dissonance and still volunteered to share knowledge with a stable perception of the organization, which helped us understand how self-efficacy would influence our positive behavior from a cognitive dissonance perspective.

\subsection{Practical Implication}

As the study showed, employees tended to maintain coherence between their cognition and behavior. Therefore, employees should control themselves from spreading unproven information about others, which could damage the relationship between colleagues and threaten the self-image of gossipers. Moreover, once employees feel dissonance and worry about their impression management, they should be guided to take some organizational desirable actions, such as proactive behavior, in the future to decrease the intensity of dissonance. Another method is to improve self-efficacy and master a problem-focus coping strategy for reducing dissonance through participating a bit challenging tasks within reach, rather than an emotion-focus strategy featured with unstable belief on self and organization. Signing up competency development training programs and absorbing advice for self-management is helpful for employees to adopt a positive attitude and increase their self-confidence and success.

When it comes to impairing the effect of negative workplace gossip, the supervisors and organization also are expected to take action. For managers, they can encourage employees to acquire real-time information, discuss openly on an online platform provided by IT-enabled tools, which shrink the perceived uncertainty, enhance psychological empowerment, and aspire to speak out bravely [81,82]. A face-to-face approach is to observe and inquire about the expectation and needs of members on different occasions, such as weekly team dinner or some informal events [2]. Both online and on-site communication is recognized as a facilitator of knowledge sharing, in turn, promoting sustainable behavior change [83]. Managers can establish work discipline in departmental meetings, cultivate a harmonious work environment, and promote organizational procedural fairness [63,84]. When encountering employees with low self-efficacy, it is necessary to assign tasks that match employees' abilities or to enhance them by verbal encouragement and setting a positive example. Enterprises can encourage knowledge sharing by increasing organizational trust. A range of efficient HRM 
practices, such as learning and development, fair performance-appraisal system, career opportunities, reasonable job design, a culture of participation, and citizenship, can enhance members' trust in the whole organization from bottom to top levels [22]. The organization can take measures to promote close interaction among employees, including regular team-building activities and job rotations. Such measures can ease relationship conflict from negative gossip at work, build impersonal trust among each other, in turn, increasing the intent of knowledge sharing [81]. If employees with low self-efficacy usually suffer dissonance from inconsistency, an organization can offer employee assistance programs (EAPS) to reduce their intrinsic dissonance through stress relief mechanisms [11,81]. These suggestions aim to strengthen the synergy between organization and member and hope members to keep a psychological contract with the organization.

\subsection{Limitations of the Study and Suggestions for Further Research}

We conducted the study to explore the mediating mechanism and moderating factors of workplace gossip influencing knowledge sharing by some questionnaires and data analysis. There were some limitations in the following aspects: first, workplace gossip in this study was taken as a kind of implicit information, which affected the tacit knowledge sharing of organization members in the formal workplace or informal workplace. In other words, the gossipers share their knowledge in an unconscious way. In fact, tacit knowledge is hard to transform into explicit knowledge, so knowledge is mainly stored and disseminated in an explicit way. Future research is expected to discuss the willingness to share explicit knowledge after gossip-talking.

Second, we adopted the mature and approved workplace gossip scale, but, at present, the scale measure on the workplace gossip in China is still in the exploration stage and lacks the clear classification standard, so future research may develop the workplace gossip scale with higher reliability and validity within the Chinese context. Moreover, all the measurements were self-reported, with a risk for a common-method variance. Still, we suggested future studies conducting a laboratory setting or longitudinal study to further verify the conclusion. Also, it was the properties and size of the sample that restricted generalizability. We presumed some control variables like education, position, tenure would have an impact on knowledge sharing, but the result showed none of them were significantly correlated, which might be caused by the limitation of region and size. Samples collected in this study were mainly from southern China, so future studies can increase the sample size and regional scope and select different types of enterprises and staff positions through a cross-culture study.

Finally, this study explored the mediating effect of organizational trust on negative workplace gossip and the moderating effect of self-efficacy from the theoretical perspective of cognitive dissonance theory, but there may be additional potential mediating effect in the process. On an individual level, people with different disposition or traits have a different attitude towards gossip [85]. For example, a study of the dark side trait discovers that people with these traits would share malicious gossip with different motivations [86]. In addition, future research is expected to conduct the cross-level study by considering organizational factors, such as organizational structure, team culture, technology factors, knowledge-intensive organization, which also have an impact on the willingness of knowledge sharing. Namely, additional research can identify the joint efforts of situational and internal factors when discussing knowledge sharing dilemma [85], to share for the organizational benefit or not to share for pro-self-advantages.

\section{Conclusions}

Based on the cognitive dissonance theory, gossipers who shared negative workplace gossip lowered their organizational trust to relieve their dissonance, which further led to less knowledge sharing. However, high self-efficacious gossipers had a better coping strategy towards dissonance and confidence about their knowledge, which buffered the effect of organizational trust on knowledge sharing. Our findings made contributions to informal communication and knowledge sharing literature by considering gossipers' cognition and personality perspectives. From this study, we remind the 
organization of potential damage due to negative workplace gossip. To minimize the effect, we advise gossipers to pay attention to their dissonance states and improve their self-efficacy, while the organization can cultivate a trustworthy atmosphere through a set of effective HRM practices.

Author Contributions: Conceptualization, C.L. and X.C.; formal analysis, X.Z. and C.L.; investigation, C.L.; methodology, X.Z. and X.C.; supervision, X.C.; validation, F.C. and H.L.; writing-original draft, X.Z., X.C. and F.C.; revision and final paper, X.Z., X.C. and F.C. All authors have read and agreed to the published version of the manuscript.

Funding: This study was funded by the Nation Natural Science Foundation of China (No. 71701080, 31970990), Nation Social Science Foundation (19GBL110) of China, and Natural Science Foundation of Guangdong Province (2017A030308013). This study was supported by the neuromanagement Laboratory of Jinan University.

Acknowledgments: In this section you can acknowledge any support given which is not covered by the author contribution or funding sections. This may include administrative and technical support, or donations in kind (e.g., materials used for experiments).

Conflicts of Interest: The authors declare no conflict of interest.

\section{Appendix A}

Table A1. Measurement.

\begin{tabular}{|c|c|}
\hline Construct & Items \\
\hline $\begin{array}{l}\text { Negative } \\
\text { Workplace } \\
\text { Gossip }\end{array}$ & $\begin{array}{l}\text { Question: In the last month, how often have you. } \\
\text { 1. Asked a work colleague if they have a negative impression of something that your } \\
\text { supervisor has. } \\
\text { 2. Questioned your supervisor's abilities while talking to a work colleague. } \\
\text { 3. Criticized your supervisor while talking to a work colleague. } \\
\text { 4. Vented to a work colleague about something that your supervisor has done. } \\
\text { 5. Told an unflattering story about your supervisor while talking to a work colleague. } \\
\text { 6. Asked a work colleague if they have a negative impression of something that another } \\
\text { co-worker has done. } \\
\text { 7. Questioned a co-worker's abilities while talking to another work colleague. } \\
\text { 8. Criticized a co-worker while talking to another work colleague. } \\
\text { 9. Vented to a work colleague about something that another co-worker has done. } \\
\text { 10. Told an unflattering story about a co-worker while talking to another work colleague. }\end{array}$ \\
\hline $\begin{array}{l}\text { Knowledge } \\
\text { Sharing }\end{array}$ & $\begin{array}{l}\text { Please indicate how frequently you shared work-related knowledge with your co-workers } \\
\text { in the past month. } \\
\text { 1. When I learned new knowledge, I told it to my colleagues. } \\
\text { 2. I shared factual knowledge (know-what) from work with my co-workers. } \\
\text { 3. I shared internal reports and other official documents with my co-workers. } \\
\text { 4. For things that were difficult to describe verbally, I demonstrated in person. } \\
\text { 5. I shared work experience with my co-workers. } \\
\text { 6. I shared know-how or tricks with co-workers. } \\
\text { 7. I shared my experience or know-how from wok with other organizational members more } \\
\text { frequently. } \\
\text { 8. I provided my know-where or know-whom at the request of other organizational members. } \\
\text { 9. I shared expertise from education or training with other organizational members in a more } \\
\text { effective way. }\end{array}$ \\
\hline Self-Efficacy & $\begin{array}{l}\text { Please rate your feelings and experience in the following descriptions. } \\
\text { 1. I always manage to solve difficult problems if I try hard enough. } \\
\text { 2. If someone opposes me, I can find means and ways to get what I want. } \\
\text { 3. It is easy for me to stick to my aims and accomplish my goals. } \\
\text { 4. I am confident that I could deal efficiently with unexpected events. } \\
\text { 5. Thanks to my resourcefulness, I know how to handle unforeseen situations. } \\
\text { 6. I can solve most problems if invest the necessary effort. } \\
\text { 7. I remain calm when facing difficulties because I can rely on my coping abilities. }\end{array}$ \\
\hline
\end{tabular}


Table A1. Cont.

\begin{tabular}{ll}
\hline Construct & Items \\
\hline 8. When I am confronted with a problem, I usually find several solutions. \\
9. If I am in a bind, I can usually think of something to do. \\
10. No matter what comes my way, I'm usually able to handle it. \\
Please evaluate your feelings and experience in the following descriptions. \\
1. I believe the company is in a position to providing benefits and looking after employees. \\
2. I believe that the company will not do anything harmful for its employees though the future \\
is uncertain. \\
3. As far as I know, most of my colleagues think that the company is trustworthy. \\
4. I believe that the company can insist on and implement its management regulations. \\
5. I believe that my supervisor is sincere in his/her attempts to meet the workers' point of view. \\
6. I believe that my supervisor is competent in his position. \\
7. I think what my supervisor said to me is reliable. \\
8. I feel quite confident that the supervisor will always try to treat me fairly. \\
9. No matter what happens, I trust that my supervisor will support and assist me. \\
10. I have full confidence in the skills of my workmates. \\
11. Most of my workmates can be relied upon to do as they say they will do. \\
Trust \\
12. If I got into difficulties at work, I know my workmates would try to help me out. \\
13. I can trust the people I work with to lend me a hand if I needed it. \\
14. I do not often trust my colleagues' promises to me (R) ${ }^{1}$.
\end{tabular}

\section{References}

1. Brady, D.L.; Brown, D.J.; Liang, L.H. Moving beyond assumptions of deviance: The reconceptualization and measurement of workplace gossip. J. Appl. Psychol. 2017, 102, 1-25. [CrossRef]

2. Kuo, C.C.; Chang, K.; Quinton, S.; Lu, C.Y.; Lee, I. Gossip in the workplace and the implications for HR management: A study of gossip and its relationship to employee cynicism. Int. J. Hum. Resour. Manag. 2015, 26, 2288-2307. [CrossRef]

3. Baumeister, R.F.; Zhang, L.; Vohs, K.D. Gossip as Cultural Learning. Rev. Gen. Psychol. 2004, 8, 111-121. [CrossRef]

4. Foster, E.K. Research on Gossip: Taxonomy, Methods, and Future Directions. Rev. Gen. Psychol. 2004, 8, 78-99. [CrossRef]

5. Robinson, S.L.; Bennett, R.J. A typology of deviant workplace behaviors: A multidimensional scaling study. Acad. Manag. J. 1995, 38, 555-572. [CrossRef]

6. Wu, X.; Kwan, H.K.; Wu, L.Z.; Ma, J. The effect of workplace negative gossip on employee proactive behavior in China: The moderating role of traditionality. J. Bus. Ethics. 2018, 148, 801-815. [CrossRef]

7. Tian, Q.T.; Song, Y.; Kwan, H.K.; Li, X. Workplace gossip and frontline employees' proactive service performance. Serv. Ind. J. 2019, 39, 25-42. [CrossRef]

8. Grosser, T.J.; Lopez-Kidwell, V.; Labianca, G.J. A social network analysis of positive and negative gossip in organizational life. Group Organ. Manag. 2010, 35, 177-212. [CrossRef]

9. Bai, Y.; Wang, J.; Chen, T.; Li, F. Learning from supervisor negative gossip: The reflective learning process and performance outcome of employee receivers. Hum. Relat. 2019. [CrossRef]

10. Beersma, B.; Van Kleef, G.A. How the Grapevine Keeps You in Line: Gossip Increases Contributions to the Group. Soc. Psychol. Pers. Sci. 2011, 2, 642-649. [CrossRef]

11. Feinberg, M.; Willer, R.; Stellar, J.E.; Keltner, D. The virtues of gossip: Reputational information sharing as prosocial behavior. J. Pers. Soc. Psychol. 2012, 102, 1015-1030. [CrossRef] [PubMed]

12. Kniffin, K.M.; Wilson, D.S. Utilities of gossip across organizational levels: Multilevel selection, free-riders, and teams. Hum. Nat. 2005, 16, 278-292. [CrossRef] [PubMed]

13. Kim, A.; Moon, J.; Shin, J. Justice Perceptions, Perceived Insider Status, and Gossip at Work: A Social Exchange Perspective. J. Bus. Res. 2019, 97, 30-42. [CrossRef]

14. Cole, J.M.; Scrivener, H. Short term effects of gossip behavior on self-esteem. Curr. Psychol. 2013, 32, $252-260$. [CrossRef] 
15. French, J.R.; Raven, B.; Cartwright, D. The bases of social power. Classics of Organization Theory; Jay, M.S., Steven, O., Yong, S.J., Eds.; Cengage Learning: Boston, MA, USA, 1959; Volume 7, pp. 311-320.

16. Zula, K.J.; Chermack, T.J. Integrative literature review: Human capital planning: A review of literature and implications for human resource development. Hum. Resour. Dev. Rev. 2007, 6, 245-262. [CrossRef]

17. Jilani, M.M.A.K.; Fan, L.; Islam, M.T.; Uddin, M. The Influence of Knowledge Sharing on Sustainable Performance: A Moderated Mediation Study. Sustainability 2020, 12, 908. [CrossRef]

18. Haseeb, M.; Hussain, H.I.; Kot, S.; Androniceanu, A.; Jermsittiparsert, K. Role of social and technological challenges in achieving a sustainable competitive advantage and sustainable business performance. Sustainability 2019, 11, 3811. [CrossRef]

19. Currie, G.; Kerrin, M. The Limits of a Technological Fix to Knowledge Management: Epistemological, Political and Cultural Issues in the Case of Intranet Implementation. Manag. Learn. 2004, 35, 9-29. [CrossRef]

20. Lu, L.; Leung, K.; Koch, P.T. Managerial Knowledge Sharing: The Role of Individual, Interpersonal, and Organizational Factors. Manag. Organ. Rev. 2006, 2, 15-41. [CrossRef]

21. Yanow, D. Translating local knowledge at organizational peripheries. Br. J. Manag. 2004, 15, 9-25. [CrossRef]

22. Vanhala, M.; Puumalainen, K.; Blomqvist, K. Impersonal trust. Pers. Rev. 2011, 40, 485-513. [CrossRef]

23. Festinger, L.; Carlsmith, J.M. Cognitive consequences of forced compliance. J. Abnorm. Soc. Psychol. 1959, 58, 203. [CrossRef] [PubMed]

24. Choi, W.; Kim, S.L.; Yun, S. A Social Exchange Perspective of Abusive Supervision and Knowledge Sharing: Investigating the Moderating Effects of Psychological Contract Fulfillment and Self-Enhancement Motive. J. Bus. Psychol. 2019, 34, 305-319. [CrossRef]

25. Wu, L.Z.; Birtch, T.A.; Chiang, F.F.; Zhang, H. Perceptions of negative workplace gossip: A self-consistency theory framework. J. Manag. 2018, 44, 1873-1898. [CrossRef]

26. Peterson, D.K. Deviant workplace behavior and the organization's ethical climate. J. Bus. Psychol. 2002, 17, 47-61. [CrossRef]

27. Nedkovski, V.; Guerci, M.; De Battisti, F.; Siletti, E. Organizational Ethical Climates and Employee's Trust in Colleagues, the Supervisor, and the Organization. J. Bus. 2017, 71, 19-26. [CrossRef]

28. Rutten, W.; Blaas-Franken, J.; Martin, H. The impact of (low) trust on knowledge sharing. J. Knowl. Manag. 2016, 20, 199-214. [CrossRef]

29. Bandura, A. Self-efficacy: Toward a unifying theory of behavioral change. Psychol. Rev. 1977, 84, 191. [CrossRef]

30. Cabrera, A.; Cabrera, E.F. Knowledge-sharing dilemmas. Organ. Stud. 2002, 23, 687-710. [CrossRef]

31. Bock, G.W.; Kim, Y.G. Breaking the Myths of Rewards: An Exploratory Study of Attitudes about Knowledge Sharing. Inf. Res. Manag. J. 2002, 15, 14-21. [CrossRef]

32. Tamjidyamcholo, A.; Baba, M.S.B.; Tamjid, H.; Gholipour, R. Information security-Professional perceptions of knowledge-sharing intention under self-efficacy, trust, reciprocity, and shared-language. Comput. Educ. 2013, 68, 223-232. [CrossRef]

33. Yeo, R.K.; Marquardt, M.J. To share or not to share? Self-perception and knowledge-sharing intent. Knowl. Manag. Res. Pract. 2015, 13, 311-328. [CrossRef]

34. Foss, N.J.; Husted, K.; Michailova, S. Governing knowledge sharing in organizations: Levels of analysis, governance mechanisms, and research directions. J. Manage. Stud. 2011, 47, 455-482. [CrossRef]

35. Hafen, S. Organizational gossip: A revolving door of regulation and resistance. South. J. Comm. 2004, 69, 223-240. [CrossRef]

36. Kurland, N.B.; Pelled, L.H. Passing the word: Toward a model of gossip and power in the workplace. Acad. Manag. Rev. 2000, 25, 428-438. [CrossRef]

37. Baumeister, R.F.; Bratslavsky, E.; Finkenauer, C.; Vohs, K.D. Bad is stronger than good. Rev. Gen. Psychol. 2001, 5, 323-370. [CrossRef]

38. McAndrew, F.T.; Bell, E.K.; Garcia, C.M. Who do we tell and whom do we tell on? Gossip as a strategy for status enhancement. J. Appl. Soc. Psychol. 2007, 37, 1562-1577. [CrossRef]

39. Ellwardt, L.; Wittek, R.; Wielers, R. Talking About the Boss: Effects of Generalized and Interpersonal Trust on Workplace Gossip. Group Organ. Manag. 2012, 37, 521-549. [CrossRef]

40. Chih-Chien, W. The influence of ethical and self-interest concerns on knowledge sharing intentions among managers: An empirical study. Int. J. Manag. 2004, 21, 370. 
41. Lin, C.P. To share or not to share: Modeling tacit knowledge sharing, its mediators and antecedents. J. Bus. Ethic. 2007, 70, 411-428. [CrossRef]

42. Ipe, M. Knowledge sharing in organizations: A conceptual framework. Hum. Resour. Dev. Rev. 2003, 2, 337-359. [CrossRef]

43. Reber, A.S. Implicit learning and tacit knowledge. J. Exp. Psychol.-Gen. 1989, 118, 219-235. [CrossRef]

44. Ambrosini, V.; Bowman, C. Tacit knowledge: Some suggestions for operationalization. J. Manag. Stud. 2001, 38, 811-829. [CrossRef]

45. McAdam, R.; Mason, B.; McCrory, J. Exploring the Dichotomies within the Tacit Knowledge Literature: Towards A Process of Tacit Knowing in Organizations. J. Knowl. Manag. 2007, 11, 43-59. [CrossRef]

46. Cabrera, E.F.; Cabrera, A. Fostering knowledge sharing through people management practices. Int. J. Hum. Resour. Man. 2005, 16, 720-735. [CrossRef]

47. Connelly, C.E.; Kelloway, E.K. Predictors of employees' perceptions of knowledge sharing cultures. Leadersh. Org. Dev. J. 2003, 24, 294-301. [CrossRef]

48. Kim, W.; Park, J. Examining structural relationships between work engagement, organizational procedural justice, knowledge sharing, and innovative work behavior for sustainable organizations. Sustainability 2017, 9, 205. [CrossRef]

49. Wang, S.; Noe, R.A. Knowledge sharing: A review and directions for future research. Hum. Resour. Manag. Rev. 2010, 20, 115-131. [CrossRef]

50. Ben-Ze'ev, A. The Vindication of Gossip. In Good Gossip; Goodman, R.F., Ben-Ze'ev, A., Eds.; University Press of Kansas: Lawrence, KS, USA, 1994; pp. 12-24.

51. Bertolotti, T.; Magnani, L. An epistemological analysis of gossip and gossip-based knowledge. Synthese 2014, 191, 4037-4067. [CrossRef]

52. Aronson, E. The return of the repressed: Dissonance theory makes a comeback. Psychol. Inq. 1992, 3, $303-311$. [CrossRef]

53. Hinojosa, A.S.; Gardner, W.L.; Walker, H.J.; Cogliser, C.; Gullifor, D. A review of cognitive dissonance theory in management research: Opportunities for further development. J. Manag. 2017, 43, 170-199. [CrossRef]

54. Greer, C.R.; Stephens, G.K. Escalation of commitment: A comparison of differences between Mexican and US decision-makers. J. Manag. 2001, 27, 51-78. [CrossRef]

55. Kammeyer-Mueller, J.D.; Simon, L.S.; Rich, B.L. The psychic cost of doing wrong: Ethical conflict, divestiture socialization, and emotional exhaustion. J. Manag. 2012, 38, 784-808. [CrossRef]

56. Elsbach, K.D.; Bhattacharya, C.B. Defining who you are by what you're not: Organizational disidentification and the National Rifle Association. Organ. Sci. 2001, 12,393-413. [CrossRef]

57. Goldberg, M.H.; Carmichael, C.L.; Hardin, C.D. Counter-argument self-efficacy predicts choice of belief-defense strategies. Eur. J. Soc. Psychol. 2020, 50, 438-447. [CrossRef]

58. Turner, M.M.; Mazur, M.A.; Wendel, N.; Winslow, R. Relational ruin or social glue? The joint effect of relational type and gossip valence on liking, trust, and expertise. Commun. Monogr. 2003, 70, 129-141. [CrossRef]

59. Sharlene Fernandes, Hansika Kapoor \& Sampada Karandikar Do We Gossip for Moral Reasons? The Intersection of Moral Foundations and Gossip. Basic Appl. Soc. Psychol. 2017, 39, 218-230. [CrossRef]

60. Kuo, C.C.; Wu, C.Y.; Lin, C.W. Supervisor workplace gossip and its impact on employees. J. Manag. Psychol. 2018, 33, 93-105. [CrossRef]

61. Zhang, R.J.; Liu, J.H.; Milojev, P.; Jung, J.; Wang, S.F.; Xie, T.; Choi, H.S.; Yamaguchi, S.; Morio, H. The structure of trust as a reflection of culture and institutional power structure: Evidence from four East Asian societies. Asian J. Soc. Psychol. 2019, 22, 59-73. [CrossRef]

62. Al-Alawi, A.I.; Al-Marzooqi, N.Y.; Mohammed, Y.F. Organizational culture and knowledge sharing: Critical success factors. J. Knowl. Manag. 2007, 11, 22-42. [CrossRef]

63. Konovsky, M.A.; Cropanzano, R. Perceived fairness of employee drug testing as a predictor of employee attitudes and job performance. J. Appl. Psychol. 1991, 76, 698. [CrossRef] [PubMed]

64. Staples, D.S.; Webster, J. Exploring the effects of trust, task interdependence and virtualness on knowledge sharing in teams. Inf. Syst. J. 2008, 18, 617-640. [CrossRef]

65. Mayer, R.C.; Davis, J.H.; Schoorman, F.D. An integrative model of organizational trust. Acad. Manag. Rev. 1995, 20, 709-734. [CrossRef] 
66. Rus, A. Trust and performance: Institutional, interpersonal and network trust. In Trust under Pressure: Empirical Investigations of Trust and Trust Building in Uncertain Circumstances; Katinka, B.F., Rosalinde, K.W., Eds.; Edward Elgar Publishing: Cheltenham, UK, 2005; pp. 80-104.

67. Samadi, B.; Wei, C.C.; Seyfee, S.; Yusoff, W.F.W. Conceptual model of organizational trust and knowledge sharing behavior among multigenerational employees. Asian Soc. Sci. 2015, 11, 32. [CrossRef]

68. Xu, Z.X.; Ma, H.K.; Wang, Y.; Li, J. Maybe I Am Not as Moral as I Thought: Calibrating Moral Identity After Immoral Action. Curr. Psychol. 2019, 38, 1347-1354. [CrossRef]

69. Noon, M.; Delbridge, R. News from behind my Hand: Gossip in Organizations. Organ. Stud. 1993, 14, $23-36$. [CrossRef]

70. Lin, M.J.J.; Hung, S.W.; Chen, C.J. Fostering the determinants of knowledge sharing in professional virtual communities. Comput. Hum. Behav. 2009, 25, 929-939. [CrossRef]

71. Svetlik, I.; Stavrou-Costea, E.; Lin, H.F. Knowledge sharing and firm innovation capability: An empirical study. Int. J. Manpow. 2007, 28, 315-332. [CrossRef]

72. Tohidinia, Z.; Mosakhani, M. Knowledge sharing behaviour and its predictors. Ind. Manage. Data Syst. 2010, 110, 611-631. [CrossRef]

73. Heuven, E.; Bakker, A.B.; Schaufeli, W.B.; Huisman, N. The role of self-efficacy in performing emotion work. J. Vocat. Behav. 2006, 69, 222-235. [CrossRef]

74. Chennamaneni, A. Determinants of Knowledge Sharing Behaviors: Developing and Testing an Integrated Model. Ph.D. Thesis, University of Texas, Arlington, TX, USA, 2007.

75. Chen, J.G. A Study on the Relationship among Organizational Trust, Organizational Justice and Organizational Citizenship Behavior of the State-Owned Enterprise Employees. Master's Thesis, Southwest Jiaotong University, Xi'an, China, 2004.

76. Zhang, J.X.; Schwarzer, R. Measuring optimistic self-beliefs: A Chinese adaptation of the General Self-Efficacy Scale. Psychologia 1995, 38, 174-181. [CrossRef]

77. Wong, S.H.; Peng, J.S. Analysis on differences of knowledge sharing behavior on demographic variables. Sci. Tech. Manag. Reser. 2012, 32, 134-138. [CrossRef]

78. Baron, R.M.; Kenny, D.A. The moderator-mediator variable distinction in social psychological research: Conceptual, strategic, and statistical considerations. J. Pers. Soc. Psychol. 1986, 51, 1173-1182. [CrossRef] [PubMed]

79. Dunbar, R.I.M. Gossip in Evolutionary Perspective. Rev. Gen. Psychol. 2004, 8, 100-110. [CrossRef]

80. Du, H.B.; Zhu, Q.; Liu, C. The effect of workplace negative gossip on proactive behavior: A moderated mediation model. Manag. Rev. 2019, 1, 190-199. [CrossRef]

81. Grosser, T.; Kidwell, V.; Labianca, G.J. Hearing it through the grapevine: Positive and negative workplace gossip. Organ. Dyn. 2012, 41, 52-61. [CrossRef]

82. Wang, W.T.; Wang, Y.S.; Chang, W.T. Investigating the effects of psychological empowerment and interpersonal conflicts on employees' knowledge sharing intentions. J. Knowl. Manag. 2019, 23, 1039-1076. [CrossRef]

83. De Bernardi, P.; Bertello, A.; Venuti, F. Online and on-site interactions within alternative food networks: Sustainability impact of knowledge-sharing practices. Sustainability 2019, 11, 1457. [CrossRef]

84. Konovsky, M.A.; Pugh, S.D. Citizenship Behavior and Social Exchange. Acad. Manage. J. 1994, 37, 656-669. [CrossRef]

85. Chae, H.; Park, J.; Choi, J.N. Two facets of conscientiousness and the knowledge sharing dilemmas in the workplace: Contrasting moderating functions of supervisor support and coworker support. J. Organ. Behav. 2019, 40, 387-399. [CrossRef]

86. Lyons, M.T.; Hughes, S. Malicious mouths? The Dark Triad and motivations for gossip. Pers. Individ. Differ. 2005, 78, 1-4. [CrossRef]

(C) 2020 by the authors. Licensee MDPI, Basel, Switzerland. This article is an open access article distributed under the terms and conditions of the Creative Commons Attribution (CC BY) license (http://creativecommons.org/licenses/by/4.0/). 